(road maintenance, gardening, public services, earetaking) and comes to the conclusion that most of these jobs cannot provide alternative employment for many manual workers who apply well beyond their middle lives.

So what can be done? Mr. Le Gros Clark has two main suggestions : That we should call into existence new categories of light work (he mentions 'paid social work' but does not define what he means by this) : and that we should work out a new social theory of retirement. In other words Mr. Le Gros Clark is now (reluctantly ?) coming to the conclusion that the period of retirement is "the inescapable third period of life" even for those who are fit and well. "We have spent much of our time studying what chances we have of preserving the health of older men and of adapting factory conditions to their changing physique. We have spent even more of our time studying the needs of the infirm and aged. It is now our business to add to these a third and equally important field of research-that into the full meaning and content of retired leisure". This may well mean a re-casting of social values.

L. S. HEARnshaw

\section{DALTON'S IRISH RIVAL}

\section{The Life and Work of William Higgins, Chemist (1763-1825)}

Including reprints of "A Comparative View of the Phlogistic and Antiphlogistic Theories" and "Observations on the Atomic Theory and Electrical Phenomena" by William Higgins. By Prof. T. S. Wheeler and Prof. J. R. Partington. Pp. viii $+173+$ xiv +496 . (London and New York: Pergamon Press, 1960.) $60 s$. net.

CHE mere sight of the title of this work will give

historians of chemistry (and especially of atomism) great satisfaction. The biographical and critical matter which makes up the modern third of the volume could probably only have been produced by this collaboration of these particular authors. The publishers are to be congratulated on reprinting in facsimile the works of William Higgins, which are discussed in every history of atomism but can in fact have been seen by only few readers. It is an appropriate tribute to one of the many Irishmen who did so much to advance science in the eighteenth century.

The history of the early chemical atomic theory is not synonymous with the work of John Dalton, although he holds the centre of the stage. It seems to us now as if some re-statement of qualitative atomism in quantitative terms were inevitable at the close of the eighteenth century. However, this is historical wisdom after the event. We are not yet certain how Dalton's mind and those of his contemporaries worked. Did Higgins anticipate Dalton? Did he influence Dalton? Davy was prepared to say that Higgins's work had been important, but his authority has little value. False notions about the historical origins of their beliefs have often been held, and are often held now, by leading authorities in experimental science. The work which brings a man scientific eminence does not necessarily make him a reliable historian, even of his own field.

The controversies in which Higgins's name was prominent began soon after Dalton's theory was put forward, which was, however, long after Higgins's first book had been published and passed over. Higgins's Comparative View of the Phlogistic and Antiphlogistic Theories was printed in 1789 in London. It was a detailed refutation of Kirwan's Essay on Phlogiston of 1787 and is remarkable in being "the first English work to support Lavoisier".

At that time the phlogistonist controversy seemed overridingly important. Twenty years later, the newer system expressed in the theoretical language of Lavoisier was supreme. Higgins's advocacy was no longer relevant and the aspect of the book which became, and remains, interesting is Higgins's use of an atomic theory in expounding his antiphlogistic views. There is no doubt that he had a notable insight into the quantitative basis of chemistry, had grasped Lavoisier's teaching well and showed some originality in combining it with atomic ideas.

In some ways he was in advance of his time (as in his views on reaction mechanisms) and might have helped to advance chemical theory if he had possessed two qualities which in fact he lacked. One was the capacity to see wherein lay the fundamental novelty of a quantitative atomic system. The other was a capacity to express himself with clarity and selfevident consistency. Dalton possessed both these qualities, and although he may have failed to see all the consequences of his own theory, he certainly opened the eyes of his contemporaries quiekly and effectively.

Dalton was recognized and honoured: in 1814 Higgins felt impelled to advance his own claims to priority by publishing his Experiments and Observations on the Atomic Theory reproduced in facsimile in this same volume. It could not give Higgins the high place he claimed, and which Wheeler and Partington conclude he could not justly claim. "Higgins has an honourable place in chemistry, but he does not stand on the same level as Dalton."

The notes, appendixes, and two sets of correlations between Comparative View of the Phlogistic and Antiphlogistic Theories and critical text are models of scholarly thoroughness. The biographical text is the first life of Higgins of any completeness.

This is not a biography for the beginner, who would in fact find much of it aridly dull. The authors have evidently not thought it necessary to extend their material by much connecting narrative or exposition intended to make its digestion easier. As an aid to study and as a record of ascertained fact, however, its faults are few.

It is not clear why the facsimile of the Comparative View of the Phlogistic and Antiphlogistic Theories is of the second edition, dated, so far as can be deciphered, 1791, when the earlier 1789 edition could have been used. So far as the text goes, however, this is unimportant, because comparison of facsimile with the first edition shows that the two are identical, errata and all. The errata have been corrected by hand in the original copy, but not in the original Atomic Theory copy. This is all of no real significance, but it is regrettable that, in my specimen at any rate, the Comparative View of the Phlogistic and Antiphlogistic Theories has lost the first page of the list of contents. The student will have to fill this small deficiency as best he may.

For the historian, yet to appear, who will write a worthy history of the early atomists, and will re-interpret them to a generation which consistently misrepresents them, this book will be an indispensable tool.
Frank Greenaway 